\title{
Physical models for classroom teaching in hydrology
}

\author{
A. Rodhe \\ Department of Earth Sciences, Uppsala University, Villavägen 16, 75236 Uppsala, Sweden \\ Correspondence to: A. Rodhe (allan.rodhe@hyd.uu.se) \\ Received: 8 March 2012 - Published in Hydrol. Earth Syst. Sci. Discuss.: 29 March 2012 \\ Revised: 2 July 2012 - Accepted: 18 August 2012 - Published: 3 September 2012
}

\begin{abstract}
Hydrology teaching benefits from the fact that many important processes can be illustrated and explained with simple physical models. A set of mobile physical models has been developed and used during many years of lecturing at basic university level teaching in hydrology. One model, with which many phenomena can be demonstrated, consists of a $1.0-\mathrm{m}$-long plexiglass container containing an about 0.25 -m-deep open sand aquifer through which water is circulated. The model can be used for showing the groundwater table and its influence on the water content in the unsaturated zone and for quantitative determination of hydraulic properties such as the storage coefficient and the saturated hydraulic conductivity. It is also well suited for discussions on the runoff process and the significance of recharge and discharge areas for groundwater. The flow paths of water and contaminant dispersion can be illustrated in tracer experiments using fluorescent or colour dye. This and a few other physical models, with suggested demonstrations and experiments, are described in this article. The finding from using models in classroom teaching is that it creates curiosity among the students, promotes discussions and most likely deepens the understanding of the basic processes.
\end{abstract}

\section{Introduction}

Many basic processes in soil water and groundwater hydrology can be illustrated with simple physical models. A household sponge may be very useful when discussing water retention or basic concepts such as field capacity and wilting point. A more elaborate model, such as a model aquifer in a plexiglass tank, can be used for experiments to determine quantities such as hydraulic conductivity and storage coefficient. The use of physical models in lecturing has many pedagogical advantages: it may rapidly clarify processes and give the students a deeper understanding of concepts and processes; it generates curiosity and interest among the students; and it allows a valuable variation in pedagogical methods. Although it normally takes more time from the lecture to show a process with a physical model than to show it with a few slides or on the blackboard, this time may be wellused time regarding the deeper understanding and more longlasting memory that can be obtained. Physical models are useful in basic undergraduate lecturing as well as in popular lecturing and lecturing for professionals. A certain demonstration can be supported by theoretical discussions at very different levels of sophistication.

There is abundant literature describing demonstrations for use in science lecturing, in particular basic chemistry (Walton, 2002) and physics. The underlying pedagogical idea for using such demonstrations is that well-motivated and wellprepared demonstrations stimulate the students' interest and help them in their scientific understanding. The positive effect of demonstrations on stimulating interest seems undisputed (Crouch et al., 2004; Di Stefano, 1996), but the educational benefits have been debated (Beall, 1996; Walton, 2002). Roberts et al. (2005) found significantly increased understanding among the students when using physical models of molecular structure in an introductory biochemistry course, and results are supported by the findings of Savec et al. (2005). Etkina et al. (2002) and Crouch et al. (2004) emphasize that the demonstration per se is not enough. A successful educational outcome requires that the students are active, for instance by making predictions before the demonstration and raising hypotheses to be tested. An interesting finding of Roberts et al. (2005) and Harris et al. (2009) was that the use of physical models promoted more sophisticated questions and discussions in the class, which then could be elaborated using advanced computer visualisation tools. 
When it comes to hydrology, the experience in using physical models in classroom teaching seems limited. Few descriptions of models for classroom teaching or student laboratory exercises in this discipline have been found in the literature. Parkinson and Reid (1987) describe an experimental sand tank developed for demonstrating the groundwater flow to drains under simulated rainfall. Tracer experiments in a tank with a confined sand aquifer are presented by Gates et al. (1996), and Werner and Roof (1994) describe student experiments with a Darcy tube.

A special requirement for models used in lecturing, as opposed to those used solely in student laboratory exercises, is that the phenomena to be shown normally must be seen almost directly, without delays. For aquifer models this may be a question of pore size, and therefore grain size. Another requirement is, of course, that the whole auditorium clearly can see (or in some cases hear) the demonstration. A selected colour of the sand, with the colour changing with the water content, as well as the use of dye for colouring water in transparent observation tubes may be helpful in this respect.

A set of mobile physical models has been developed and used during many years of lecturing in basic level university courses in hydrology. The aim of this article is to describe some of these models and present demonstrations and experiments suitable for lectures. Many of the experiments can also be done as student laboratory exercises, but the focus of this article is their use during lectures. The article describes the major elements of the models, but not the technical details.

\section{Demonstrations with equipment not requiring special constructions}

Before describing the more elaborate models, a few demonstrations with equipment that can be found in the lab or in the kitchen are described.

Three cans filled with well-sorted sand, well-sorted gravel and a mixture of the sand and gravel respectively are shown. How would one determine the porosity? Which soil has the largest porosity? A rough determination of the porosity is made by measuring the amount of water needed to saturate the originally dry soils. The porosity of the sand and gravel is about the same, whereas that of the mixture is smaller, since some of the pore space between the large grains is filled with sand. The water retention of the soils can then be shown by opening filtered holes in the bottom of the cans, originally closed by tape. With a soil thickness less than the height of the capillary fringe, the sand and the mixture give only a few drips, corresponding to the volume of free water on the saturated surface, whereas most water in the gravel is drained. The cans should be made of soft plastic, so that they can be squeezed a little in order to purge air entrapped by the infiltrating water.
A household sponge, e.g. $4 \mathrm{~cm} \times 7 \mathrm{~cm} \times 10 \mathrm{~cm}$, is well suited for discussions on field capacity, plant available water and wilting point, as well as for more advanced discussions on the influence of the groundwater table on the water content in the unsaturated zone. The discussions can be initiated by turning the sponge in different ways. If the sponge is at field capacity in a "lying" position, it will start to drip when turned into a "standing" position. Can anybody explain? When "lying", no pores are exposed to a more negative pressure head than the thickness of the sponge, in this case $-4 \mathrm{~cm}$. When "standing", the pores in the uppermost part are exposed to a negative pressure head equal to the length of the sponge $(-10 \mathrm{~cm})$, causing drainage of large pores in the upper part. The sponge can also be used for a tracer experiment. By infiltrating coloured water from a squeeze bottle into the wet sponge, the concept of piston flow and the difference between the rapid pressure propagation velocity and the comparatively slow particle velocity can be shown. Dripping from the sponge starts very soon, whereas the colour front proceeds slowly down through the "soil" profile.

\section{Model for basic concepts in groundwater and soil water}

This model represents an unconfined sand aquifer. It consists of a plexiglass tank $(100 \mathrm{~cm} \times 10 \mathrm{~cm} \times 40 \mathrm{~cm})$ filled with sand, through which water is circulated in a closed system (Fig. 1). Inlet and outlet heads are regulated by height adjustable containers. These head regulators are supplied with water pumped from a reservoir under the aquifer. The water levels in the regulators are kept constant by overflow pipes, with excess water spilling back to the reservoir. A submersible bail pump, operated by a $12 \mathrm{~V}$ car battery, is located in the reservoir. The groundwater level (or more precisely, the piezometric head near the bottom of the aquifer) is seen as the water level in transparent piezometer tubes along the aquifer. Apart from the inflow/outflow points at the bottom of the sidewalls of the tank, there is a "well", i.e. an outflow point connected to a plastic tube, near the bottom at the centre of the aquifer. The inlet and outlets of the tank are equipped with nylon weave filters. The model aquifer, with its water circulation system, is placed on a trolley so that it easily can be moved between lecture halls.

There are certain requirements for the texture of the soil used in the model with regards to hydraulic conductivity and water retention properties. Looking at the hydraulic conductivity only, it must be high enough to give a quick response in the groundwater level and groundwater flow due to changes in the boundary conditions (heads, rate of simulated rainfall). Furthermore, the flow through the aquifer should be possible to measure volumetrically with a reasonable accuracy and rapidity. A flow of some $0.11 \mathrm{~min}^{-1}$ has been found appropriate. The lateral particle velocity should be high enough to allow tracer experiments during the lecture. The hydraulic 


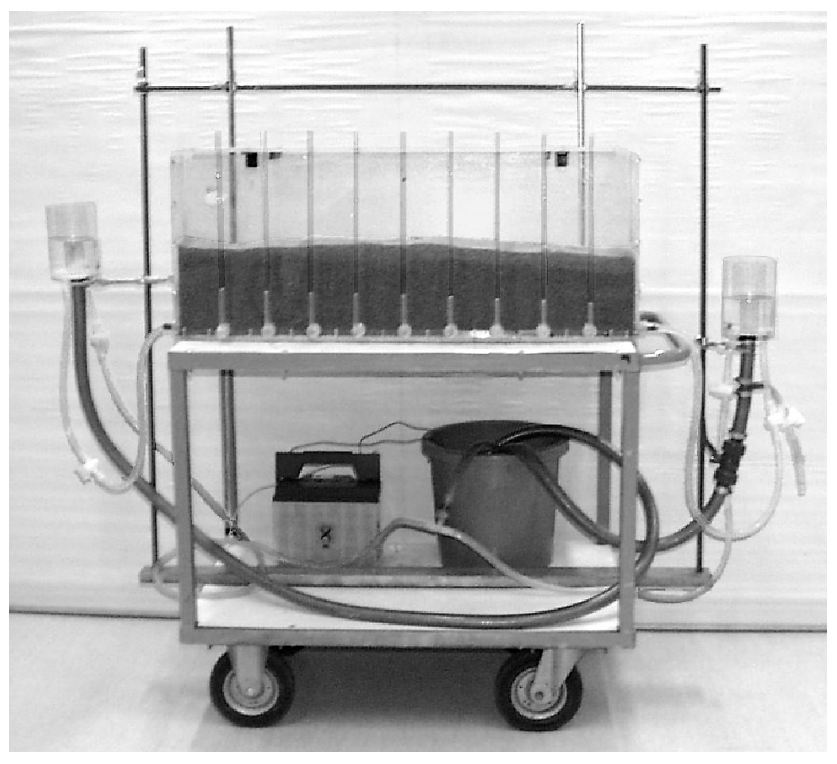

Fig. 1. Sand aquifer for classroom demonstrations.

conductivity should, on the other hand, not be so high that impractically high flow rates are needed in order to give gradients in the water table large enough to be clearly seen by the class from the water levels in the observation tubes.

To show processes in the unsaturated zone, the water retention properties should be such that there is a considerable vertical variation in the water content in this zone. Thus, the capillary fringe should not reach the ground surface (which requires large pores), but the pores should still contain a considerable amount of water (requiring sufficiently small pores). For demonstrations of lateral groundwater flow, it is important that the thickness of the capillary fringe is small compared to the thickness of the groundwater zone. The lateral head gradient in the capillary fringe is the same as in the saturated zone, and the hydraulic conductivity is almost as large as in the saturated zone. If the capillary fringe is relatively thick, a considerable fraction of the total lateral flow takes place in the unsaturated zone, above the groundwater table. In such a case, calculations of hydraulic conductivity, and discussions of the shape of the groundwater table, may not be correct if they are based on the thickness of the truly saturated zone, as defined by the groundwater level. The fact that the effect of the capillary fringe is relatively more important in the model than in reality is probably a general problem with small sand aquifer models.

From experience it has been found that a fairly wellsorted sand with a dominating grain size of about $0.5-2 \mathrm{~mm}$ gives an acceptable compromise of the above requirements. For the sand used here, the hydraulic conductivity is about $5 \times 10^{-3} \mathrm{~m} \mathrm{~s}^{-1}$ and the capillary fringe is about $6 \mathrm{~cm}$. The sand is light brown and its colour darkens drastically as it approaches saturation.

\subsection{Demonstrations}

\subsubsection{Definition of the groundwater table and unsaturated and saturated zones}

The groundwater level is adjusted to $0.1 \mathrm{~m}$ above the bottom of the tank. The inlet and outlet are closed. A pit is dug by hand, while pointing out that the sand is moist (sticks to the fingers) but that no water collects in the pit. At a certain depth, a water table develops in the pit - this is the groundwater table by definition (also shown by the water levels in the observation wells). The dark colour, indicating saturation or near saturation, is the same above and below the groundwater table due to capillary effects, showing that the groundwater table is not defined by water content but by water pressure. By inserting a rapidly responding tensiometer, the negative pressure head in the unsaturated zone can be shown.

At later stages in the lecture, the relationship between pressure head and height above the groundwater table can be discussed and demonstrated with the tensiometer in, or slightly above, the capillary fringe. If there is no vertical flow, then at every point in the unsaturated zone the total head equals the groundwater level and the pressure head equals the negative value of the height above the groundwater table. The total head, $\Phi$, is given by

$\Phi=\Psi+z$

where $\Psi$ is pressure head $(\mathrm{m})$ and $z$ is height $(\mathrm{m})$ above a reference level. With no vertical flow, $\frac{\mathrm{d} \Phi}{\mathrm{d} z}=0$. Since, by definition, $\Psi=0$ at the groundwater table, we get by integration $\Psi=-\left(z-z_{\mathrm{g}}\right)$ where $z_{\mathrm{g}}$ is the height of the groundwater table.

\subsubsection{Storage coefficient}

The storage coefficient (for unconfined aquifers equal to the specific yield) is easily determined by measuring the change of the groundwater level for a certain change in storage, e.g. for a certain extracted volume of water.

$M=\frac{\Delta S}{\Delta h}$

where $\Delta S$ is the change in storage (m) (collected drainage per unit horizontal area of the aquifer) and $\Delta h$ is the change of the groundwater level (m).

In order to deepen the understanding of processes in the unsaturated zone, two similar determinations can be made. The first experiment starts with the groundwater level very close to the ground surface, giving a small storage coefficient, in this sand around 2-4\%. Before the second experiment, the water table has been lowered to about $10 \mathrm{~cm}$ below the ground surface. The storage coefficient this time will be around $20 \%$, a more representative value for this coarse sand. Can anybody among the students explain the reasons for the different results? 
In the first experiment, the top of the capillary fringe never came below the ground surface, and only a few large pores were drained. In the second experiment, the upper part of the unsaturated zone was exposed to a negative pressure head for which a considerable pore volume of this sand is drained. The difference is illustrated by the drainage equilibrium curves (water retention curves) in Fig. 2. The second experiment gives the "normal" storage coefficient, equal to the specific yield of the sand. On the other hand, the first experiment shows the very small storage coefficient, with a consequently rapid and large response of the groundwater table to a certain water input, that may occur in areas with a very shallow groundwater (see Gillham (1984) for a discussion on this phenomenon as a possible mechanism for streamflow generation).

When the water table is lowered a certain distance, $\Delta h$, from a level near the ground surface (Fig. 2, left), the change in water storage in the unsaturated and saturated zones $(\Delta S$, represented by the blue areas between the graphs) is very small. When the water table is lowered from a deeper level (Fig. 2, right), the same lowering gives a much larger change in storage.

\subsubsection{Darcy's law with the Dupuit assumption}

A head gradient along the aquifer is generated by opening the inflow and outflow and adjusting the height of the head regulating containers. Due to the geometric configuration, the flow is roughly horizontal and the Dupuit assumption of vertically constant heads applies. A rough estimate of the hydraulic conductivity from the Darcy equation in one dimension gives a good opportunity to discuss the various terms in the equation.

$Q=-K A \frac{\mathrm{d} h}{\mathrm{~d} x}$

The groundwater flow, $Q\left(\mathrm{~m}^{3} \mathrm{~s}^{-1}\right)$, is measured volumetrically at the outlet from the aquifer. The cross-sectional area $A$ $\left(\mathrm{m}^{2}\right)$ for the flow is measured at the centre of the aquifer, and the slope of the groundwater table $\mathrm{d} h / \mathrm{d} x$ is determined from the difference in groundwater level, $\Delta h$, in two tubes, symmetrically located around the centre separated by the distance $\Delta x$. As discussed above, the cross-sectional area for the flow is larger than the thickness of the groundwater zone. This will overestimate the hydraulic conductivity, but this problem is preferably omitted at this stage in order to concentrate on the basic equation. In a real aquifer this effect is negligible.

A close look at the groundwater levels may reveal that the groundwater table is not linear, but that it becomes progressively steeper in the direction of the flow. This can be discussed from Eq. (1). With a decreasing $A$ (seen as a decreasing $h$ ) and a constant $K$, the absolute value of $\mathrm{d} h / \mathrm{d} x$ must increase in order to maintain a constant $Q$. The expression for the groundwater table is obtained by integration of Eq. (1), using $A=h b$ where $h$ is the height of the groundwater table

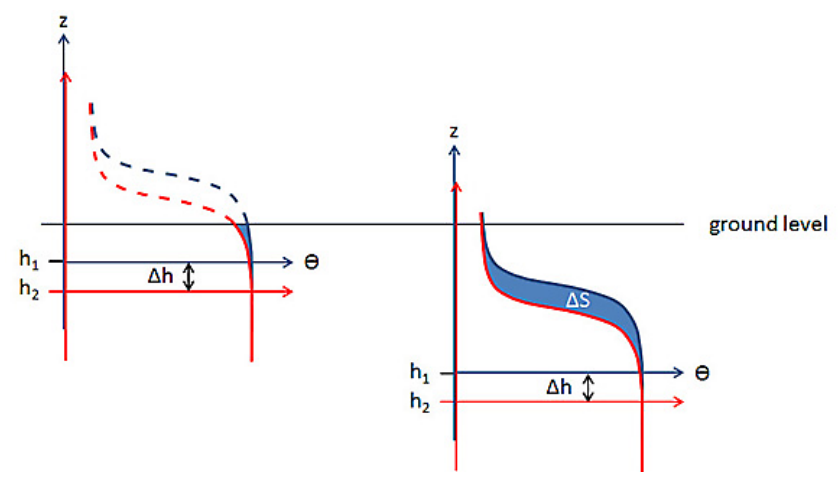

Fig. 2. Equilibrium soil moisture profiles for different levels, h, of the groundwater table. $z$ is height and $\theta$ is volumetric water content. The broken lines above the ground surface are parts of the water retention curve, showing the water content that would have been at these levels if the soil would have continued up to the level.

above the bottom (m) and $b$ is the width considered (in this case $0.1 \mathrm{~m}$ ) giving

$h=\left(h_{\mathrm{o}}^{2}-\frac{2 Q}{K b}\left(x-x_{\mathrm{o}}\right)\right)^{\frac{1}{2}}$

where $h_{\mathrm{o}}$ is the height of the groundwater table above the aquifer bottom at $x=x_{0}$.

When determining $K$ directly from Eq. (3) as described above, the cross-sectional area $A$ was measured midway between the tubes for measuring $h$. This "intuitive" strategy differs slightly from the exact solution of Eq. (4). Squaring both sides of the equation and solving for $Q$ gives

$Q=-K \frac{h_{\mathrm{o}}+h}{2} b \frac{h-h_{\mathrm{o}}}{x-x_{\mathrm{o}}}=-K A_{\mathrm{m}} \frac{\Delta h}{\Delta x}$.

Here $A_{\mathrm{m}}=h_{\mathrm{m}} b$, where $h_{\mathrm{m}}$ is the arithmetic mean of the two observed groundwater levels. Since the groundwater table is not linear, but upward convex, this mean value is slightly smaller than the midway value used. The difference is, however, small in this application and does not significantly affect the result.

\subsubsection{Pumping test}

Illustrative pumping tests can be done by putting the head regulators at the same level and "pumping" the aquifer by opening the drainage tube located in the middle of the aquifer. Non-equilibrium as well as equilibrium tests can be shown and the drawdown and recovery discussed. The pumping rate, $Q$, is selected by adjusting the height of the free end of the drainage tube. The flow in this aquifer can be considered one-dimensional, but it is not difficult to imagine and discuss qualitatively the principles for the more common radial pumping test. The constant head in the head regulators, which supply the water, corresponds to positive hydraulic boundaries. The effect of a negative hydraulic boundary can 
be shown by closing one of the inlets, giving larger and more rapid drawdown and a very different recovery at that side. The equation for the equilibrium water table, from which the hydraulic conductivity can be determined, is given by Eq. (4). If $Q$ is the rate of pumping, then $Q$ in the equation is replaced by $Q / 2$, since the well receives water from two sides.

\subsubsection{Streamflow generation - recharge and discharge areas}

The ground surface is arranged to form a hillslope along the model. The supplying heads are adjusted to generate a sloping groundwater table reaching the ground surface and a stream (cross section) at the foot of the hillslope (Fig. 3). An intense rainfall at the top of the hillslope is generated by the hand-shower. The groundwater table rises rapidly along the hillslope, and groundwater is discharged to the stream both directly and through the saturated discharge area bordering the stream. The increased groundwater discharge in response to the infiltration is seen by the class as erosion and material transport in the saturated discharge area.

The setup provides a good opportunity to demonstrate and discuss recharge and discharge areas, the flow paths of water to the stream, and the roles of groundwater flow, saturation overland flow and channel precipitation in streamflow generation. Rainfall just outside the recharge area, where the capillary fringe reaches the ground surface, gives a rapid and large response of the groundwater table and groundwater discharge (the capillary fringe model (Gillham, 1984) as commented above). Rainfall high up in the recharge area gives a slightly delayed and much smaller response of the groundwater table as compared to the conditions downhill, due to temporary storage in the unsaturated zone and larger storage coefficient. It can be hypothesized that infiltration in the boundary area between recharge and discharge areas, where the soil moisture is high due to shallow groundwater table, is responsible for the dynamic response of groundwater in streamflow generation. The role of infiltration in the upper part of the recharge area is to maintain base flow between storm flow events (see experiments in real hillslopes by Corbett et al. (1975) and discussions by Rodhe (1989)). It should be emphasised that this demonstration is just an illustration of a plausible view of streamflow generation in humid catchments. The mechanisms in the model are quite evident, but the step from this simplified model hillslope to a real one is, of course, far too big to allow far-reaching conclusions to be drawn on "how it works" in reality.

\subsubsection{Flow lines and particle velocity}

The demonstration of streamflow generation showed the very rapid response of the groundwater discharge to infiltration, which was just a few seconds in the model and may be on the order of hours in a real hillslope. It will, on the other hand, take some 10-20 min for the water molecules infiltrating in

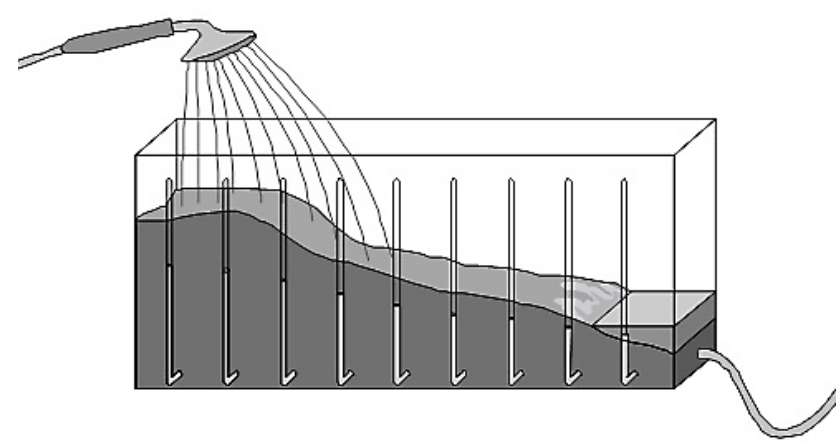

Fig. 3. Demonstration of streamflow generation in a hillslope.

the upper part of the hillslope to reach the discharge area and the stream (this is not seen in the demonstration). In a real hillslope, the corresponding time may be several months. The only way to get direct information on these questions is by tracer experiments. It may be difficult to find time for such experiments during a lecture, but if such time can be found they can be very illustrative.

Fluorescent dye gives the most beautiful and detailed view of the tracer movement and dispersion, but also caramel colour can be used. The use of fluorescent dye is somewhat complicated since it requires illumination by ultraviolet light. This light could be either from a bright sky outside the windows or, more effectively, from a UV-lamp in a blacked out room. The tracer is injected close to the frontal wall of the model in slugs at a few depths in the groundwater zone. Even if the tracer is injected as slugs and not continuously (which of course could be arranged), it is easy to imagine the flow lines since the slugs are elongated along the flow directions. A good fluorescent tracer is fluorescein sodium. As pointed out above, the plexiglass of the model must be of the right quality when using fluorescent dye in this experiment, since not all such materials allow penetration of UV-light.

From the roughly observed velocity of the tracer clouds, $v_{\mathrm{p}}\left(\mathrm{m} \mathrm{s}^{-1}\right)$, a rough estimate of the kinematic porosity, $p_{\mathrm{k}}$, is obtained from the relationship

$v_{\mathrm{p}}=\frac{Q}{A p_{\mathrm{k}}}$.

A kinematic porosity around $40 \%$ is obtained for the sand used, which agrees acceptably well with the porosity determined volumetrically on a sample of the sand. The kinematic porosity, defined by Eq. (6), represents the total porosity minus a possible fraction of immobile water which can be neglected in this coarse sand.

The significance of the lateral flow in the capillary fringe can be shown in a tracer experiment. Tracer injected a few $\mathrm{cm}$ above the groundwater table moves with almost the same velocity as a tracer injected below the groundwater table. As commented above, in this experimental setup, the lateral head gradient in the unsaturated zone is the same as in the 
groundwater zone and the hydraulic conductivity of the capillary fringe is very near the saturated hydraulic conductivity.

\section{Unconfined aquifer for two-dimensional flow}

Experiments with focus on the two-dimensional flow pattern under steady-state flow conditions can be performed with a tank containing an open sand aquifer that is deeper than the one in the groundwater tank described above (Fig. 4). This plexiglass tank $(100 \mathrm{~cm} \times 10 \mathrm{~cm} \times 45 \mathrm{~cm})$ is connected to a similar closed flow system, and the levels of the inlet and outlet can be selected depending on the character of the flow pattern to be illustrated. The frontal wall of the tank has piezometers in a quadratic grid in which the height of the water level can be read in transparent plastic tubes outside the wall. The height above a certain level, e.g. the table, gives the total head in relation to that level. Equipotential lines are obtained by interpolation between the observed head values, and the corresponding flow lines are drawn perpendicular to the equipotential lines. The so-derived flow lines can be compared to the flow lines observed by tracer experiments. This visual evidence of downward flow in the recharge area and upward flow in the discharge area can give an "aha-experience" to the students! It is to be noted that, for homogenous and isotropic conditions, the flow pattern is independent of the hydraulic conductivity and can be derived from continuity conditions and the linear relationship between flow and head gradient. The hydraulic conductivity determines the flow needed to maintain the flow pattern.

The ground surface can be arranged in various ways in order to illustrate different phenomena. With small lakes at the inlet and outlet, the vertical flow components in these areas can be discussed as well as the near horizontal flow lines in the central part of the tank. Here the equipotential lines are close to vertical, the head equals the groundwater level, and the head gradient is thus given by the slope of the groundwater table, i.e. the Dupuit assumption is valid. With a straight sloping ground surface and a water supply that saturates the soil to the ground surface along the whole slope, the flow pattern caused by groundwater recharge by rainfall over the surface is shown. In this case there is only a small region in the central part where the vertical flow components can be disregarded. This might look discouraging when it comes to the application of the Dupuit assumption, but it should be emphasized that the thickness-to-length ratio of this aquifer is strongly exaggerated. With the much smaller thickness-tolength ratio of a real aquifer, the vertical flow components are less predominant and over a large area the head gradient is given by the slope of the water table.

The flow pattern in a homogeneous aquifer with a lake is illustrated in Fig. 5. The effect of the lake is to attract the flow lines. The (very small) head gradient over the lake generates a larger flow through the lake than what can be supplied by groundwater from the corresponding cross section

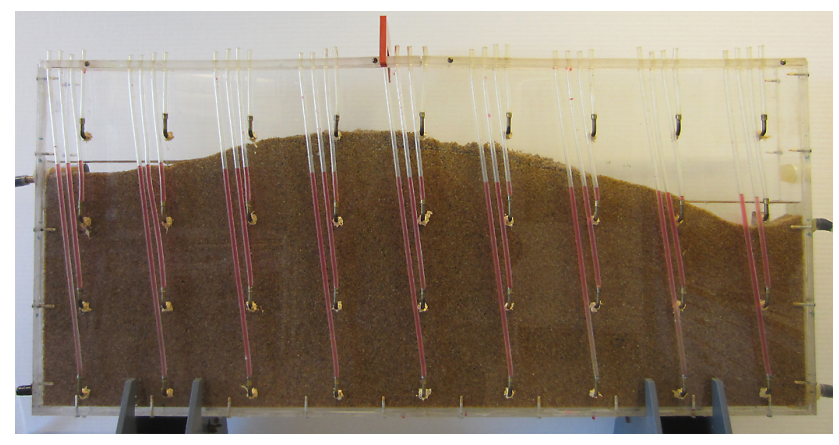

Fig. 4. Tank for two-dimensional groundwater flow. The water in the piezometric tubes is coloured in order to make the water levels visible for the class. A close look at the figure reveals that the total head decreases with depth below the recharge lake on the left-hand side of the tank, whereas the total head increases with depth below the discharge lake on the right-hand side. In the centre of the tank, there is no vertical difference and the total head equals the groundwater level.

of the aquifer. In terms of flow nets, the bottom of the lake is an equipotential surface, which the flow lines are crossing under right angles. If the lake is shallow enough, the flow lines closest to the bottom of the aquifer are not affected by the lake. It should be noted the flow pattern sketched in Fig. 5 presumes homogeneous and isotropic hydraulic conductivity. The fine sediments of a real lake would probably represent a layer with reduced hydraulic conductivity which would reduce the diverting effect of the lake on the flow pattern.

Experiments with two-dimensional flow are well suited for a few hours of laboratory exercise for the students, since a detailed analysis of the head is needed to derive the equipotential lines and the implied flow pattern. The experiment can, however, also be performed during the short time available in a lecture. A student reads the levels and the teacher notes the heads in a coordinate system over the aquifer prepared on the blackboard before the lecture. The equipotential lines and groundwater surface can be drawn by rough interpolation between the observed head values while explaining three rules:

1. The lake bottom is an equipotential surface, with the total head equal to the height of the water surface.

2. The walls and the bottom of the tank represent flow lines, and the equipotential lines meet them under right angles.

3. At the groundwater surface, the pressure head is zero implying that the total head equals the elevation head. The groundwater level is thus located where the equipotential line reaches the same elevation as the head it represents.

When the equipotential lines have been drawn, the flow lines can be drawn crossing the equipotential lines under right angles. 


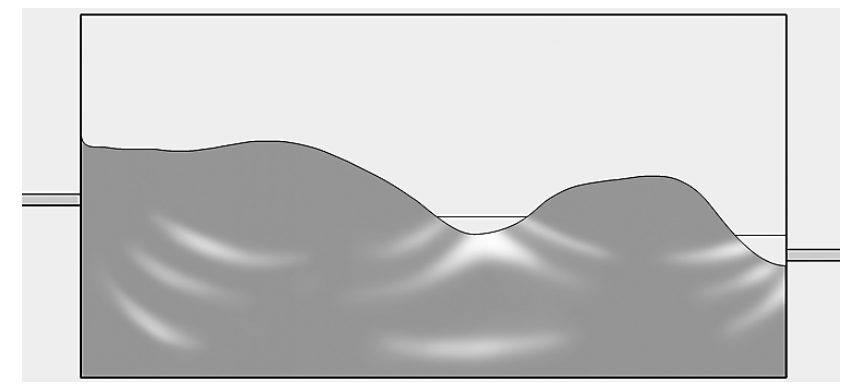

Fig. 5. A tracer experiment with schematically drawn tracer clouds (flow lines) from tracer injections at different depths performed at different times or different locations.

\section{Tank for phenomena in the unsaturated zone}

The apparatus described below has been developed to demonstrate an unexpected phenomenon in unsaturated flow, the capillary barrier (Fig. 6) (e.g. Ross, 1990). A plexiglass tank $(50 \mathrm{~cm} \times 4 \mathrm{~cm} \times 45 \mathrm{~cm})$, with freely draining openings near the bottom of the sidewalls, contains a layered soil profile with fine sand above a coarse sand along a sloping interface. At levels below the lowest part of the sloping interface, the fine sand is separated from the coarse sand by an impermeable vertical wall. The bottom half of the tank thus has two compartments, with fine and coarse sand respectively, each with its own drainage opening. Rapidly responding tensiometers have been installed from the back wall along verticals through the sand and through sand and gravel respectively. The head at the tensiometer sites is shown as the water level in transparent plastic tubes in front of the tank. A "rainfall simulator" consisting of a series of taps along a tube with water supply is located above the ground surface.

\section{A coarse layer diverts unsaturated flow}

Before the lecture the tank is saturated by water and allowed to drain until the dripping stops, i.e. to drainage equilibrium. In order to avoid the problem of entrapped air in the profile, the saturation is made by filling the tank with water from below, by connecting water supply tubes to the drainage openings. The tensiometer tubes will be filled by water when the tank is saturated; if necessary, their free ends are lowered to allow drainage in order to get away air from the tubes.

When the profile is at drainage equilibrium, the demonstration starts by simulating a moderate rainfall from one or two valves on top of the left-hand side of the tank. After a little while, the right drainage outlet, i.e. the one in the fine sand, will start to drip. No dripping will occur from the drainage opening on the coarse sand side until, after some discussions, the rainfall is increased by further opening the rainfall taps. Soon the flow from the gravel side will start, and this flow will be much larger than the flow from the sand. When the rainfall is decreased, the flow from the gravel ceases. The demonstration shows that, at a sufficiently low

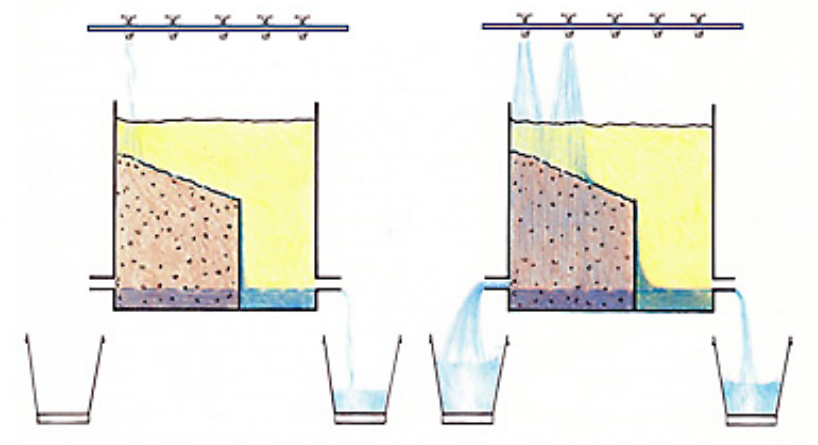

Fig. 6. Tank with fine sand (yellow colour) and coarse sand (brown) to show the effect of a coarse layer on unsaturated flow. The flows are greatly exaggerated in this principle sketch (Modified from Grip and Rodhe, 1994).

pressure potential, the hydraulic conductivity of the coarse sand is small as compared to that of the fine sand (due to low water content) and it is easier for the water to flow along the sloping bottom of the sand than to penetrate vertically into the gravel. Only water-filled pores can conduct water.

In a more advanced discussion, the phenomenon can be explained from differences between sand and gravel in the relationship between hydraulic conductivity, $K$, and pressure head, $\Psi$. Before the demonstration, with the profile at drainage equilibrium, the total head, $\Phi$, in all points equals the height of the drainage openings, and the water level in all tubes is at this level. While starting the demonstration, with a moderate rainfall, attention is paid to the response of the tensiometers. The rainfall is adjusted so that $\Psi$ just above and just below the interface between the fine and coarse sand is about $-10 \mathrm{~cm}$. When the rainfall is increased, the pressure head increases (becomes less negative) as seen by increasing water levels in the tensiometer tubes. When $\Psi$ is around $-5 \mathrm{~cm}$, the outlet from the coarse sand starts to drip. In both flow situations, the total head gradient is directed from the fine sand into the coarse sand, but it is only when the unsaturated hydraulic conductivity of the coarse sand becomes large enough, due to high water content, that a considerable flow into the gravel starts. The two situations are shown schematically in the $K-\Psi$ relationships in Fig. 7.

For demonstration purposes, the right part of the tank can be treated as a vertical homogeneous profile. With rainfall at this part only, the apparatus can be used for general discussions on relationships between head gradients, pressure head, unsaturated hydraulic conductivity and flow. These demonstrations require tensiometers that react very quickly. The tensiometers developed for this tank are made of sintered kaolin and have an air entry pressure of about $-70 \mathrm{~cm}$. 


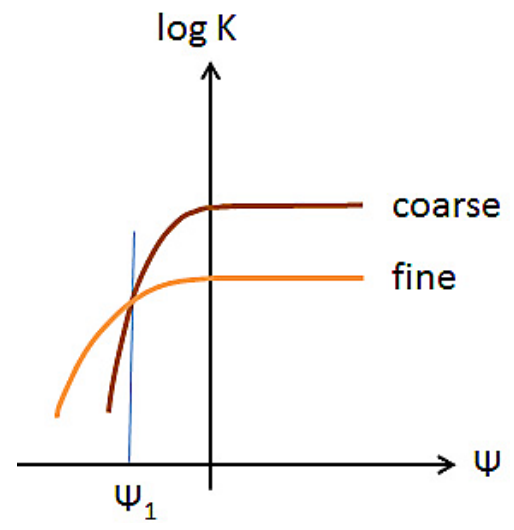

Fig. 7. Schematic relationship between hydraulic conductivity $(K)$ and pressure head $(\Psi)$ for coarse and fine sand. By regulating the rate of rainfall such that $\Psi$ is above or well below $\Psi_{1}$, it can be determined whether the flow will enter the coarse sand or be diverted along the bottom of the fine sand layer.

\section{Concluding remarks}

Many processes in soil water and groundwater flow and storage can be shown during a lecture with equipment of various degrees of sophistication. The equipment and demonstrations described in this article have been developed for use at the basic level university teaching in hydrology. They have also been successfully used in popular science lectures and lectures for school classes at different levels. One specific possibility when using the models is to identify and discuss misconceptions of water occurrence and flow in the landscape. Such misconceptions are quite common (e.g. Dickerson et al., 2005), and discussing them is an important part of the teaching process (Reinfried et al., 2012).

It is my experience that the physical models and demonstrations give a good base for discussions with the students and a pedagogically valuable variety in the means of lecturing.

Training and preparation are needed for the lecturer, but it is well worth this effort considering the deeper understanding of the processes that can be obtained, not only for the students but also for the teacher.

Acknowledgements. The equipment and demonstrations described in this article have been developed and used during many years of lecturing for hydrology classes at Uppsala University. I wish to thank the students for good discussions and the appreciation shown. My thanks also go to Sigvard Andersson at the Swedish Agricultural University, who inspired me as a student with his excellent demonstration lectures, and to Sören Karlsson at the Department of Earth Sciences, Uppsala University, who created most of the equipment and always found solutions to technical problems at any level.

Edited by: S. Uhlenbrook

\section{References}

Beall, H.: Report on the WPI Conference "Demonstrations as a teaching tool in chemistry: Pro and con”, J. Chem. Educ., 73, 641-642, 1996.

Corbett, E. S., Sopper, W., and Lynch, J. A.: Watershed response to partial area applications of simulated rainfall, The Hydrological Characteristics of River Basins/Les caractéristiques hydrologiques des bassins fluviaux, IAHS Publ., 117, 63-73, 1975.

Crouch, C. H., Fagen, A. H., Callan, J. P., and Mazur, E.: Classroom demonstrations: Learning tools or entertainment?, Am. J. Phys., 72, 835-838, 2004.

Di Stefano, R.: Preliminary IUPP results: Student reactions to inclass demonstrations and to presentation of coherent themes, Am. J. Phys., 64, 58-68, 1996.

Dickerson, D., Callahan, T. J., Van Sickle, M., and Hay, G.: Students' conceptions of scale regarding groundwater, J. Geosci. Educ., 54, 374-380, 2005.

Etkina, E., Van Heuvelen, A., Brooks, D. T., and Mills, D.: Role of experiments in physics instruction - A process approach, Phys. Teach., 40, 351-355, 2002.

Gates, A. E., Langford, A. P., Hodgson, R. M., and Driscoll, J. J.: Ground-water-simulation apparatus for introductory and advanced courses in environmental geology, J. Geosci. Educ., 44, 559-564, 1996.

Gillham, R. W.: The capillary fringe and its effect on the water-table response, J. Hydrol., 67, 307-324, 1984.

Grip, H. and Rodhe, A.: Vattnets väg från regn till bäck (In Swedish, English title: Water's journey from rain to stream), Hallgren och Fallgren, Uppsala, Sweden, 156 pp., 1994.

Harris, M. A., Peck, R. F., Colton, S., Morris, J., Neto, E. C., and Kallio, J.: A combination of hand-held models and computer imaging programs helps students answer oral questions about molecular structure and function: A controlled investigation of student learning, CBE-Life Sci. Educ., 8, 29-43, 2009.

Parkinson, R. and Reid, I.: A physical model for shallow groundwater studies and the simulation of land drain performance, J. Geogr. Higher Edu., 11, 125-132, 1987.

Reinfried, S., Tempelmann, S., and Aeschbacher, U.: Addressing secondary school students' everyday ideas about freshwater springs in order to develop an instructional tool to promote conceptual reconstruction, Hydrol. Earth Syst. Sci., 16, 1365-1377, doi:10.5194/hess-16-1365-2012, 2012.

Roberts, J. R., Hagedorn, E., Dillenburg, P., Patrick, M., and Herman, T.: Physical models enhance molecular three-dimensional literacy in an introductory biochemistry course, Biochem. Mol. Biol. Edu., 33, 105-110, 2005.

Rodhe, A.: On the generation of stream runoff in till soils, Nord. Hydrol., 20, 1-8, 1989.

Ross, B.: The diversion capacity of capillary barriers, Water Resour. Res., 26, 2625-2629, 1990.

Savec, V. F., Vrtacnik, M., and Gilbert, J. K.: Evaluating the educational value of molecular structure representations, in: Visualisation in Science Education, edited by: Gilbert, J. K., Springer, 269-300, 2005.

Walton, P. H.: On the use of chemical demonstrations in lectures, University Chemistry Education, 6, 22-27, 2002.

Werner, A. and Roof, S. R.: Using Darcy flow tubes to teach concepts of ground-water geology, J. Geol. Educ., 42, 220-224, 1994. 